\title{
Foreign Language Learning and Teaching Based on Cognitive Psychology
}

\author{
Guo Liu \\ School of Foreign Languages, Jiujiang University, Jiujiang, 332005
}

\begin{abstract}
Cognitive psychology refers to the process that people process the information symbol by brain and its main theoretical goal is to explain the information processing method during human activity. In English teaching, cognitive psychology pays more attention to the driving role of concept and situational role of textbook, which is the further development of students' intelligence for the purpose of improving students' competence for language use. Based on this, the foreign language learning and teaching based on cognitive psychology is discussed in this paper.
\end{abstract}

Key words: Cognitive psychology; foreign language learning; teaching

At present, psychological cognition discipline and English teaching activity form a new teaching method, which is to analyze the influence of students' learning experience and learning method on the academic performance by studying the relevant theoretical factors in English teaching. From the perspective of cognitive psychology, the analysis and study of English teaching activity can better connect the two disciplines and better serve the English teaching.

\section{Introduction of cognitive psychology}

Cognitive psychology was developed in the 20th century and became an important discipline of western psychological research later. It is the psychological process of human in the cognition of a certain thing, which explains the psychological reaction activity and language performance of human in the cognitive process by modification, acquisition, processing and information storage method with memory, language, attention and other senior psychological reaction as the psychological research object and content. At present, people answer the various knowledge in the cognitive process by information transfer process, human perception process and thing comprehension method, that is, cognitive psychology is mainly to study the human psychological mechanism and is the input and output of human psychological information. The process of analysis and speculation of human psychological process and phenomenon is the core idea of psychology. 
As cognitive psychology is developed on the basis of language development and modern information processing method and language is a dominated and constrained system symbol, the learning method of language should be mastered in the learning process. The relevant experts of cognitive psychology think learning is actually that the cognitive behavior organizes the information and then continuously understands and processes the acquired information; knowledge refers to the integration of the psychological experience, psychological structure and knowledge by using the association of objective things and interaction in the teaching process. The relevant scholars think the psychological cognition means to learn the knowledge of related disciplines and then evaluate and convert the knowledge. Some other scholars think learning is to form a cognition of the structure of external things and then form new knowledge structure system after fragmentation and integration. Therefore, in English teaching, the organic combination of English teaching and psychology can make English teaching effective and scientific. In English education, the influence of cognitive psychology on students' intelligence is generally stresses and students' English level is cultivated by improving their understanding and use of language rules.

\section{Influence of cognitive psychology on teaching in English teaching}

\section{Cognitive English teaching method}

In the cognitive English teaching, it is required to conduct in-depth practice and learning on the basis of the mastering of language rules and the understanding of language, take students as the center of English teaching, and correct and analyze the wrong understanding. As cognitive psychology is roughly the same with the cognitive thinking and is an expression way of cognitive psychology thinking, it is mainly embodied in the following contents in the practical English teaching: (1) it pays more attention to the role of behavior in the human cognitive structure; (2) the structure of English language can be mastered and understood by analyzing English vocabulary, pronunciation and grammar and it is allowed to develop in the situational development by using the language competence. The language practice can be conducted by using the sentence structure; (3) in the cognition of English psychology theory, the significance of learning activity is highlighted.

\section{Narrative teaching}

In English teaching, the narrative teaching is generally divided into three stages. The first stage is the classical student teaching, in which the literary structure and theory are mainly studied; 
the second stage is the post-classical narrative teaching, in which the teaching practice factors are situational; the third stage is the cross-medium and narrative theorization, in which the multiple developing disciplines are integrated. The narrative development refers to a process of the cognition of a thing, which is the understanding of natural occurrence of the thing, but the teaching method combining the English teaching and narrative teaching includes several teaching concepts and teaching thoughts: (1) it is the narration of the whole English teaching process, which manifests the English classroom situation in a narrative way. Students' listening, speaking, memory and expression abilities are improved and their learning initiative is driven by making them participate in the narrative teaching. (2) It is the enhancement, supplement and perfection of

multiple English teaching methods. (3) Narrative English teaching is mainly to present the teaching behavior between students and teacher and English and conduct narrative management and monitoring of knowledge and information.

\section{Relationship between construction of socialism and cognitive psychology}

In English teaching, the use of modern education psychology theory in the English teaching is the main goal of building the socialist teaching method. The construction of socialist English includes the following contents: (1) students can acquire English knowledge and skills; (2) students can interact with the society and better cooperate with others; (3) cognitive theory imposes great influences on the whole learning process of students, including students' learning environment, content. The knowledge construction also decides students' learning. In the teaching process, the guidance of experience can create a good learning atmosphere and environment for students.

\section{Guidance of cognitive psychology on English teaching}

\section{Highlight the situational features of textbook in teaching}

From the perspective of cognitive psychology, the situational models of some materials in the textbook are presented to the students in a procedure way and students are required to pay attention to the features of different situations selectively, which can not only make them better perceive and understand the textbook, but also pay more attention to students' situational features, that is, process the emphasized symbol information. In the cognitive learning theory, the best way is to let students experience, feel and practice in the realistic society if they want to build the essential significance of knowledge learned because students can obtain the learning experiences 
directly through the practical application in the real life, get more learning experiences through constant practice and better absorb and master and deeply understand the knowledge obtained through practice. The educational effects are not obvious if students simply listen to the teacher's explanation of experience. For teaching, this research is to make students actively build the knowledge structure in their mind, rather than memorize what the teacher teachers mechanically so as to establish better teaching strategy and promote the teaching development.

\section{Highlight the driving role of concept in teaching}

It can be seen from the basic principles of cognitive psychology that the information processing needs the concept driving in addition to data driving. Contemporary American psychologists think students' learning is mainly to accept learning and the acquisition of new knowledge mainly depends on the interaction of old knowledge and concept in the current structure and the addition of new knowledge to the original cognitive structure. Cognitive structure is directly added to the interaction with the new knowledge, which does not only decide whether the new learning ability is produced, but also ensure the migration of new knowledge in the new environment. In the learning process, there are mainly two learning methods: one is the comprehension learning method and the other is the mechanical learning method, that is, cognitive learning. This kind of learning method can effectively understand the association between learning rules and learning concept of knowledge learned. From the perspective of psychology, the comprehension learning method is a more effective learning method, which can make students master the relevant knowledge learned firmly.

\section{Emphasize students' cognitive method}

In the teaching process, the cognitive method is different due to the difference of individuals, which can be divided into two classes: field independence and field dependence. People, with field independent cognitive method, will take the reference information as the processing basis in the process of cognitive activity. This kind of person is independent and can reorganize the provided information in case of internal needs or situational needs, that is, reorganize the symbolic imagery and perceptual imagery, to make it consistent with the current task. People, with field dependent cognitive method, will take external reference as the basis for information processing in the cognitive process, that is, see what the symbolic imagery is. This kind of person is of poor self-concept and the learning effect of English course will reduce obviously in case of negative 
reinforcement.

\section{Emphasize students’ cognitive structure in teaching}

The educational learning of students is mainly to make students flexibly apply the knowledge learned in the new situation. It is found by research that the learning with certain meaning is based on the existing learning. In the meaningful learning process, the features of original cognitive structure is the main factors that affect the learning. For example, in English teaching, the teacher should take the situational features of textbook as the key points, create teaching situations by using some more intuitive teaching methods and teaching tools and provide perceptual experiences. The creation of teaching situations can not only effectively improve students' learning interest and make the whole teaching process more communicative and situational, but also create a good English teaching environment for students, improve students’ English use and enhance the English teaching effects and process so as to improve the English teaching quality. In addition, it can make students have the cognitive basis of mastering the concept. 


\section{Improvement of English classroom teaching under the cognitive psychology theory}

\section{Form cognitive schema in students' mind}

To effectively improve students' learning effects, the teacher can build a knowledge framework and then connect the new English knowledge and old knowledge organically by this knowledge framework, so as to make students develop a higher knowledge level from an original knowledge level. In the English teaching process, the teacher should constantly consider the English language form and text content in addition to the internal structure of textbook.

\section{Create independent learning environment for students}

In the teaching process, the teacher should realize that the learning is to build a cognitive structure in students' mind and students should not be regarded as the container that learns and accepts knowledge. In addition to the knowledge authority, the teacher is also the organizer, guider and supervisor that guides the students to build the knowledge cognition. Therefore, the teacher should change the previous teaching mode that the teacher teaches and the students accept and guide students step by step from simple to complex according to the cognitive level of different students and students' cognitive development rule on the basis of organizing the teaching structure in the teaching process.

\section{Provide situations that conform to the real life}

In the teaching process, the teacher should use real scenarios in the real life for teaching. As the content of real scenarios integrates various skills and knowledge, students can better use the knowledge learned and be clear about the significance and correlation of knowledge learned. In addition, only the materials that really exist in the life can fully mobilize students' learning initiative. In the actual implementation process, the teacher should do the following: (1) the teacher should provide the relevant clues of solving problems for students. The purpose of education is to cultivate people good at learning and people are required to have good knowledge level in the future society. Therefore, the teacher should not tell the students the method of solving problems directly, but guide them to conduct thinking independently to solve the problems in the teaching process. (2) The teacher should provide a real scenario to students, conduct teaching with the problems or events in the real life and provide real and vivid teaching scene for students by multimedia tool and network technology so as to stimulate students' initiative and curiosity and make students learn and explore actively. (3) The teacher should guide the students to learn 
actively. In the teaching process, the teacher should guide the students to practice continuously after providing the real life task to find out the material and information channel. (4) The teacher should ask students to conduct discussion and reflection, compare and evaluate the thinking process of themselves and others to find the advantages and disadvantages, summarize their learning method and predict the situation in the future.

\section{Conclusion}

All in all, in English teaching, cognitive psychology theory plays an important role in guiding the English teaching, so English teacher should realize the importance of cognitive psychology in the teaching process so as to give full play to students' learning ability more effectively and scientifically and make students get good teaching results more easily.

\section{References:}

[1] J.R.Anderson. Cognitive Psychology[M]. Translated by Yang Qing, Zhang Shuzu. Changchun: Jilin Education Publishing House, 1989:65-69.

[2] Pi Liansheng. Educational Psychology[M]. Shanghai: Shanghai Educational Publishing House, 1998:231-235.

[3] Pi Liansheng. Beyond Bloom——on Measurement and Evaluation of Learning Outcomes in "Knowledge Classification and Goal-Oriented" Teaching[J].Journal of East China Normal University, 2000,(02):40-49.

[4] Yang Huiying, Tashi Nima, Wang Xiaoli, Cong Xiaoming. Research on Cultivating Students’ Foreign Language Learning Ability by Scaffolding Teaching[J]. Journal of Inner Mongolia Normal University (Educational Science), 2014 (05):127-129.

[5] Pu Lijuan. On Relationship between Knowledge View of Modern Cognitive Psychology and Creativity[J]. Yunnan Education, 2002,(05):9-12. 